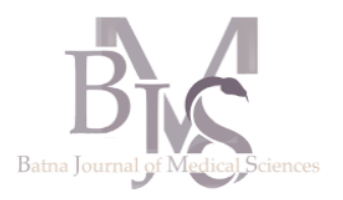

\title{
Les examens de laboratoire en hématologie
}

\author{
Hematology laboratory investigations
Mohamed Brahimi ${ }^{1}$, Farah Bouamama ${ }^{1}$, Assia Alem ${ }^{1}$, Amel Mihoubi ${ }^{1,2}$, Mohamed Amine Bekadja ${ }^{1}$.

${ }^{1}$ Hematology and Cell Therapy Department, EHU "1er Novembre 1954" Oran, Algeria.

2 Biotechnology Department, University of Oran, Algeria.

\section{Correspondance à :}

Mohamed BRAHIMI

bmw73dz@yahoo.fr

DOI :https://doi.org/10.48087/ BJMStf.2015.2216

Il s'agit d'un article en libre accès distribué selon les termes de la licence Creative Commons Attribution International License (CC BY 4.0), qui autorise une utilisation, une distribution et une reproduction sans restriction sur tout support ou format, à condition que l'auteur original et la revue soient dûment crédités.

\section{RÉSUMÉ}

La Formule de Numération Sanguine (FNS) et la coagulation sont les tests de laboratoire les plus effectués. Ces deux examens doivent être effectués systématiquement à diverses reprises puisque de nombreux troubles sanguins peuvent être pauci ou asymptomatiques et toutes les maladies peuvent conduire à leur perturbation. Pour ces raisons, ces tests sont décrits dans le présent document. De nos jours, la majorité des FNS sont effectuées à l'aide des paramètres de dix-huit compteurs automatiques. Pour des raisons pédagogiques, ces paramètres sont divisés en trois parties : globules rouges, globules blancs et plaquettes et la perturbation de chacun est mise en évidence ci-après. Les tests de coagulation standard (TCA, TP et fibrinogène) sont décrits et l'approche clinique est expliquée dans cette monographie.

Mots clés : explorations hématologiques, Formule de Numération Sanguine, Tests de la coagulation.

\begin{abstract}
Complete blood cell count (CBC) and coagulation screening tests are the most performed laboratory tests. These two assays must be done systematically in various occasions since many blood disorders can be pauci or asymptomatic, and every illness may lead to their disturbance. For these reasons these tests are described in this paper. Nowadays, the majority of CBCs are performed using eighteen parameters automatic counters. For pedagogic reasons, this load of parameters is divided into three parts: red blood cells (RBCs), white blood cells (WBCs) and platelets parameters and the alteration of each of these later are highlighted hereafter. Standard coagulation assays (aPPT, PT and fibrinogen) are described and clinical approach explained in this monograph.
\end{abstract}

Keywords: Hematology Investigations, Complete Blood Count, Coagulation screening assays.

\section{الفحوصات المخبرية لأمراض الدم}

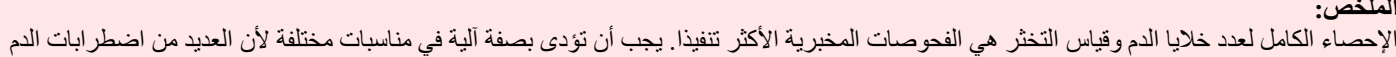

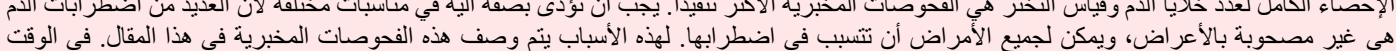

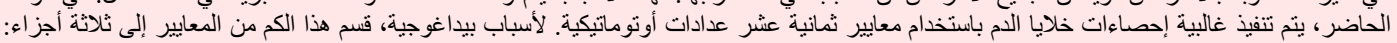

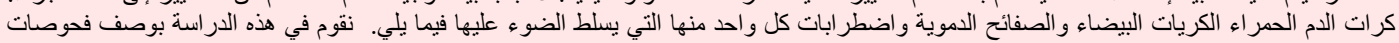

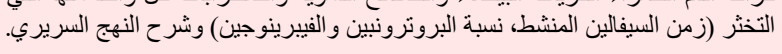

الكلمات المفتاحية: فحوصات الدم، إحصاء عدد خلايا الدم الكامل، قياس التخثر.

\section{INTRODUCTION}

With a complete blood cell count (CBC) and coagulation screening tests (aPTT, PT and fibrinogen), the majority of blood disorders can be screened. These tests should be performed systematically in many situations such as pre surgical investigations, pre-employment checkup, that is because many hematological diseases can be pauci or asymptomatic, for instance: in chronic lymphoctic leukemia, which is one of the most frequent hematological malignancies in Europe (1), lymphocytosis can be the only sign of the illness. Another example is patients with mild hemophilia A or B; they have levels of factor VIII or IX at 10 to $30 \%$ (2), generally are asymptomatic but they can be exposed to a lifethreatening hemorrhage if they undergo surgery or experience a major trauma. For these reasons, all physicians must be well aware of when and how to check these laboratory parameters.

\section{COMPLETE BLOOD CELL COUNT (CBC)}

CBC is the most performed laboratory test in medical investigations since every illness can lead to a cell count disturbance. In order to perform a CBC, blood sample should be redrawn in a tube containing ethylenediaminetetra-acetic acid ( $\mathrm{k} 2$ or $\mathrm{k} 3$-edta) because this irreversible calcium-binding anticoagulant hinders platelet aggregation so that platelets are evenly spread and their numbers can be assessed more easily (3). In addition, white and red blood cells shapes are better preserved than in other anticoagulant.

In the past, blood counts were performed by slow and labor-intensive manual techniques using counting chambers, microscopes, glass tubes, colorimeters, centrifuges and a few simple reagents. Nowadays, the automated blood counters replaced these old laborious techniques (3). These instruments are able to measure and calculate at least eighteen 
parameters and draw three distribution histograms simultaneously by impedance in few seconds (using the socalled Coulter principle) (4). However, some instruments can perform until 45 parameters. Physician can by confused by the amount of data delivered by the laboratory and their usefulness in everyday practice. However, some disorders must not be misdetected. All these parameters can be divided into three parts:

\section{Red blood cells (RBC)s parameters}

The blood counters measure the RBC count, the hemoglobin level $(\mathrm{Hb})$ and the mean cell volume (MCV). The other parameters such as: hematocrit (Hct), mean cell hemoglobin $(\mathrm{MCH})$, mean cell hemoglobin concentration (MCHC) and the red cells distribution width (RDW) are calculated using the measured ones (5), these later are less and less used in routine practice. In case of an anemia (i.e. Decreased level of $\mathrm{Hb})$, the MCV must be considered and then according to the MCV value a multitude of decisions can be taken (6). Figure 1 shows the clinical approach to anemia.

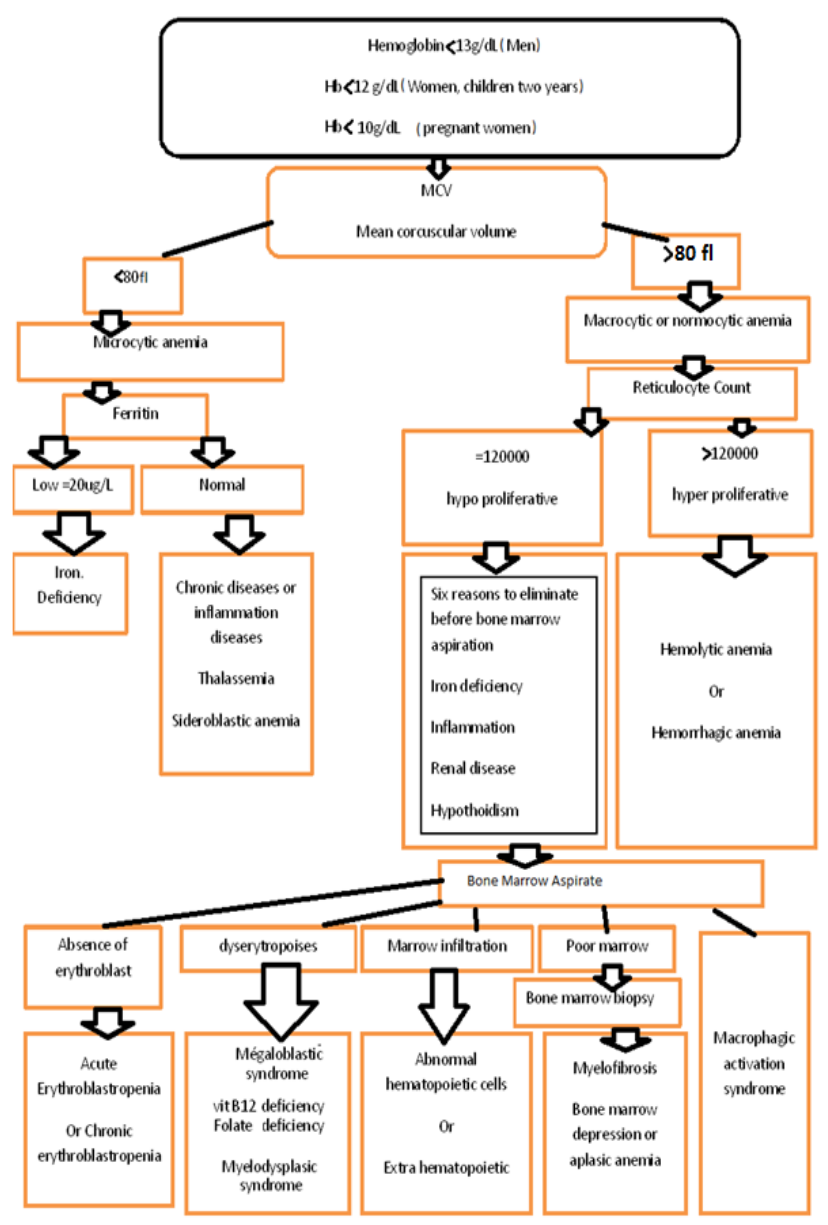

Figure 1: Clinical approach to anemia

Another very important hematology parameter is the reticulocyte count, which is recommended in case of a normocytic (MCV: 80 to $100 \mathrm{fl}$ ) or a macrocytic anemia (MCV above 100fl) since it is the most effective means of assessing red cell generation (5). This count is usually done manually but, in some laboratories, can be executed by a big automatic CBC instrument with a quite good reliability but not with an eighteen parameters counter (3).

The RDW is a mathematical calculation that gives insight into the amount of anisocytosis (variation in size) and, to some degree, poikilocytosis (variation in shape) in a peripheral smear. The RDW is derived as follows: RDW= (standard deviation of $\mathrm{RBC} / \mathrm{MCV}) \times 100$. The normal value for $\mathrm{rdw}$ is $11.5 \%$ to $14.5 \%(5)$.

Erythrocytosis is defined as an increase in total red cell mass (RCM). It is suspected by finding a raised haematocrit (Hct) (packed cell volume, PCV). The term 'polycythaemia' is widely used synonymously but lacks precision and can lead to confusion. Polycythaemia vera (PV) is a neoplastic clonal disorder of the bone marrow stem cell causing excessive proliferation of the erythroid, myeloid and megakaryocyte lineages and carrying a risk of thrombotic complications. Persistent elevation of hct above $48 \%$ in adult female and above $51 \%$ in adult male is abnormal. To be noted that Hct can be elevated with a normal $\mathrm{rcm}$ if plasma volume is reduced (7). Table 1 shows the classification of polycythemia.

Table 1: Classification of Erythrocytosis

\begin{tabular}{|c|c|c|}
\hline \multirow{2}{*}{$\begin{array}{l}\text { Primary } \\
\text { erythrocytosis }\end{array}$} & Congenital & Truncation of erythropoietin recep \\
\hline & Acquired & $\begin{array}{l}\text { Polycythaemia vera (PV) } \\
\text { (syn. polycythaemia rubra vera (PR } \\
\text { primary proliferative polycythaem } \\
\text { (PPP)). }\end{array}$ \\
\hline $\begin{array}{l}\text { Secondary } \\
\text { erythrocytosis (SE) } \\
\text { due to high }\end{array}$ & Congenital & $\begin{array}{l}\text { High oxygen-affinity haemoglobin } \\
\text { Congenital low 2,3-DPG } \\
\text { Autonomous high Epo production }\end{array}$ \\
\hline
\end{tabular}

endogenous

erythropoeitin

production

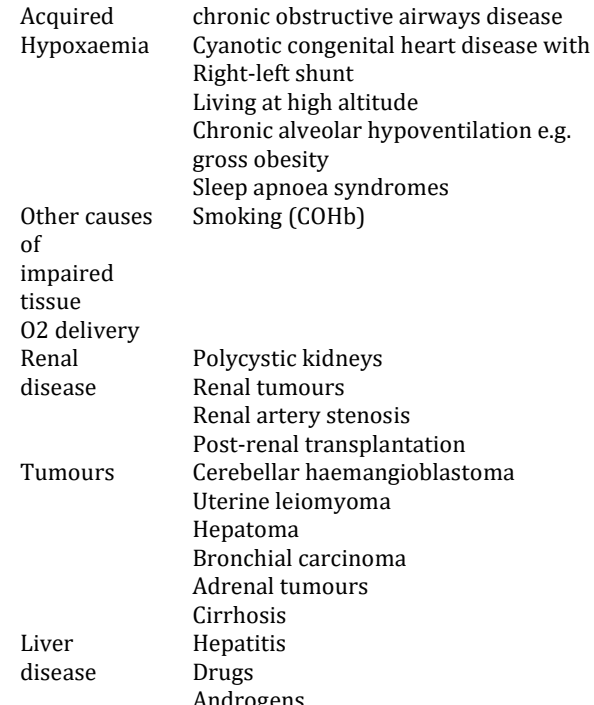

Idiopathic

erythrocytosis (IE)

Persistent high RCM, no cause found but no evidence of myeloproliferative disease or clear cause of secondary erythrocytosis.

Relative

erythrocytosis (RE)

Syn. apparent

polycythaemia

spurious

erythrocytosis

pseudopolycythaemia

Normal RCM and low plasma volume Diuretic therapy or dehydration Gaisbock's syndrome

Smoking, alcohol, hypertension,

obesity.

\section{White blood cells (WBC) parameters:}

The WBCs are counted after RBC lysis and the size-referenced WBC histograms display the classification of leukocytes according to size following lysis, not the native cell size. The lytic agent lyses the cell and the cytoplasm collapses around the nucleus, producing differential shrinkage. The histogram subpopulations reflect the sorting of the cells by their relative size, which is primarily their nuclear size. The differentiation 
Table 2: Clinical situations that can lead to WBC differential count disturbance.

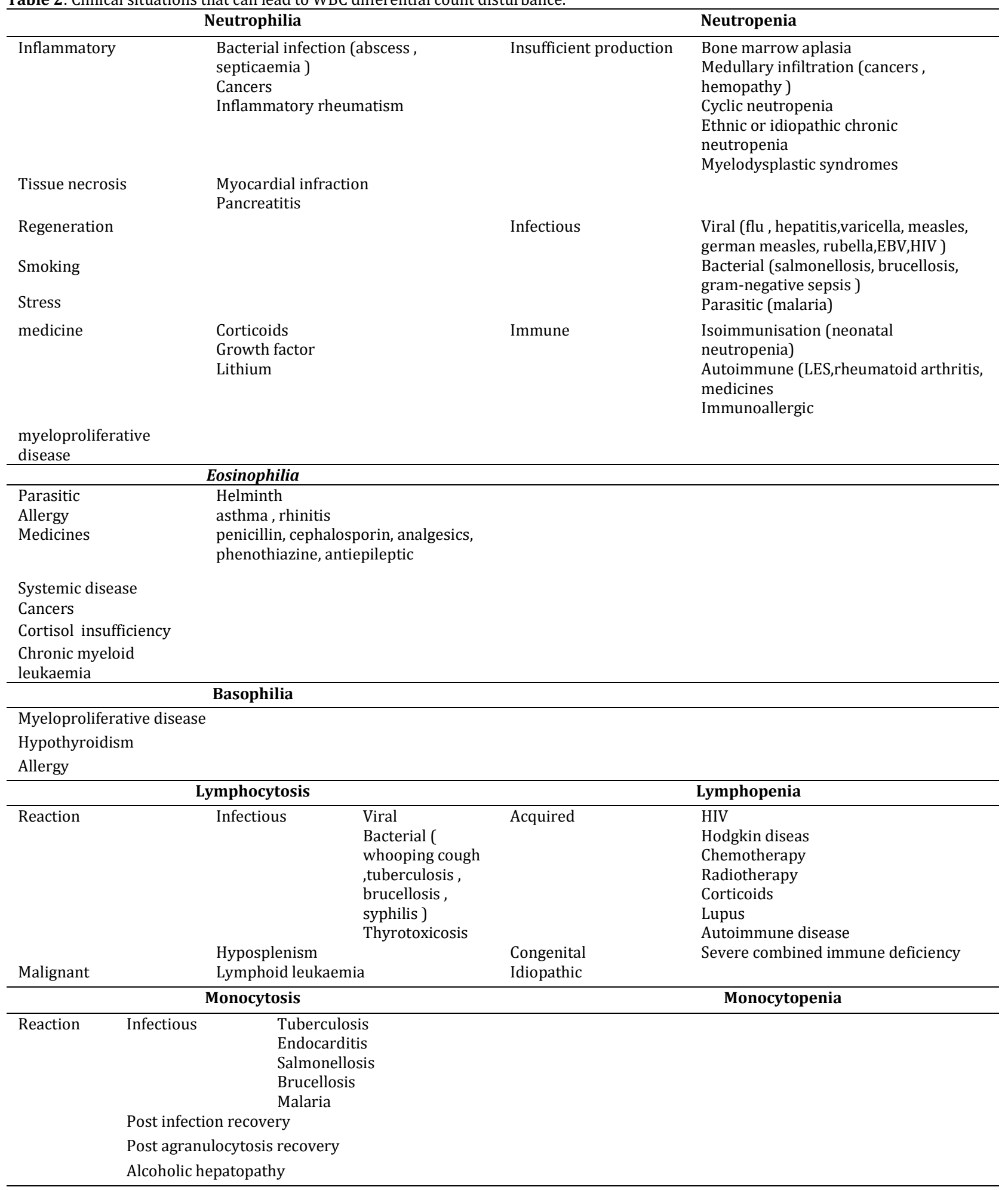

is as follows: lymphocytes (35-90 fl), mononuclear $(90-160$ $\mathrm{fl})$ and granulocyte (160-450 fl) (8).

Automated counters express the differential counts of WBCs in percentages and in their absolute counts. According to the international council for standardization in hematology (ICSH) only the absolute count must be considered and interpreted (9). Table 2 shows clinical situations that can lead to WBC differential count disturbance.

\section{Platelets parameters}

Platelets and RBCs are counted and sized in the same channel and since platelets are the smallest elements of the blood these later are recognized according to their size (3); however, it must be kept in mind that obtaining an accurate platelet count by using an automated hematology analyzer may be complicated by the presence of particles of similar size and/or light scatter properties (red cell fragments, microcytic red cells, apoptotic white blood cell fragments) and by giant platelets and platelet clumps $(10,11)$; for these reasons microscopic validation of platelet counts is an important component of the blood smear review. In the past we proposed a fast and reliable platelet count estimation technique from blood smear (12).

In case of a thrombocytopenia confirmed on a blood film a 
bone morrow smear must be reviewed in order to determine the mechanism of thrombocytopenia (decreased production or increased consumption of platelets) (13).

Thrombocytosis is defined as a platelet count of over $450000 / \mu \mathrm{l}$; it may be due to a primary myeloproliferative disorder or a secondary reactive feature. The patient's history and clinical examination may reveal features of the condition to which the elevated platelet count is secondary. CBC (i.e. the other parameters) may provide useful information such as: marked leucocytosis with left shift (in the absence of a history of infection), basophilia or an elevated Hct and RBC count are highly suggestive of a myeloproliferative disorder when associated with thrombocytosis. It is unusual for reactive thrombocytosis to cause a platelet count above $106 / \mu \mathrm{l}(7)$. Table 3 shows different etiologies in case of thrombocytosis.

Table 3: Different etiologies in case of thrombocytosis

\begin{tabular}{ll}
\hline Myeloproliferative disorders & $\begin{array}{l}\text { Disorders associated with elevated } \\
\text { platelet count }\end{array}$ \\
\hline Primary thrombocythaemia & Hemorrhage \\
Polycythaemia rubra vera & Trauma \\
Chronic granulocytic leukemia & Surgery \\
Idiopathic myelofibrosis & Iron deficiency anemia \\
& Malignancy (lung cancer, breast cancer \\
& Hodgkin's disease) \\
& Acute chronic infection \\
& Inflammatory disease e.g. rheumatoid \\
& arthritis, ulcerative colitis Post- \\
& splenectomy \\
& Rebound in response to cytapheresis \\
& and/or chemotherapy. \\
\hline
\end{tabular}

\section{BLOOD SMEAR}

Even the most expensive and accurate hematology analyzers are not designed to eliminate peripheral blood film evaluation, and microscopic review of the blood smears is an important part of the diagnosis of hematology disorders (12).

A blood film may be made from non-anticoagulated (capillary) blood, or from edta-anticoagulated blood. A drop of blood is spread on a glass slide and then stained with maygrünwald-giemsa (MGG), romanowsky or wright's stain (3). While examining a blood smear WBC and platelets counts can be estimated, this is not the case of RBCs since their number are in millions/ $\mu$ l. However, the slide must be entirely and carefully scanned for morphological aberrancies of RBCs, WBCs, and platelets.

\section{BONE MARROW EXAMINATION}

This is a cytologic preparation of bone marrow cells obtained by aspiration of the marrow and a smear of the cells, allowing excellent visualization of cell morphology and enumeration of the marrow cellular elements (14). The bone marrow aspirates is an invasive procedure that is why it should be always wisely indicated.

Common indications for bone marrow aspiration are 1) Hypoplastic normocytic or macrocytic anemia 2) unexplained anemia, leucopenia or thrombocytopenia after deep investigation. 3) $\mathrm{Bi}$ or pancytopenia. 4) Abnormal cell findings, such as blasts, on the peripheral smear. 5) If multiple myeloma is suspected (bone lesions, monoclonal gammapathy).

\section{COAGULATION SCREENING ASSAYS}

All coagulation tests are performed on citrated plasma, most commonly obtained using blue-top vacuum blood-collection tubes that pull in nine parts of blood to one part citrate (5). The international society for thrombosis and haemostasis recommends the routine use of $3.2 \%$ sodium citrate (5). This reversible calcium-binding anticoagulant can be easily inactivated by the addition of calcium $(\mathrm{CaCl} 2)$, the clotting will restart immediately after this adjunction (13).

The vast majority of important bleeding disorders, secondary to clotting defects, can be excluded if the findings are all normal for prothrombin time (PT), activated partial thromboplastin time (aPTT), fibrinogen or thrombin time (15). These tests will reveal congenital or acquired deficiency of coagulation factors, which can be confirmed by specific assay (15).

Every time clotting assays are mentioned, the "Y" coagulation cascade (extrinsic and intrinsic pathways) is described and illustrated $(13,14,16,17)$; therefore, there is no need to be once more illustrated here. However, it must be kept in mind even if a new in-vivo coagulation mechanism had been introduced this last decade (17) the "Y" scheme is still helpful for the in-vitro mechanism.

Partial thromboplastin time (PTT) and activated partial thromboplastin time (aPTT) are used to test the intrinsic and common pathways of coagulation. Nevertheless, in aPTT, an activator is added that speeds up the clotting time and results in a narrower reference range. The aPTT is considered a more sensitive version of the PTT and is used to monitor the patient's response to heparin therapy (18).

The production of fibrin by means of the extrinsic and common pathways requires tissue factor and factor vii, in addition to factors $\mathrm{X}$ and $\mathrm{V}$, prothrombin, and fibrinogen. These pathways are measured by the prothrombin time (PT). $(14,16,18)$ this chronometric assay, time of clotting measured in seconds, can be converted into a percentage.

PT explores three out of four vitamin $\mathrm{K}$ dependent factors, so it is not amazing that this screening test is used to monitor vitamin $\mathrm{K}$ antagonists therapy such as Warferin or Sintrom (13).

Since different laboratories use different reagents, the best way to monitor anti-vitamin $\mathrm{K}$ therapy is to use the "International Normalized Ratio" (INR). The INR is a mathematical method of standardizing PT obtained from different laboratories, and it is calculated using the following formula: $\quad \mathrm{INR}=\left(\mathrm{PT}_{\text {patient }} / \mathrm{PT}_{\text {normal }} \text { control }\right)^{\mathrm{ISI}}$. The ISI (International Sensibility Index) is known for each pt laboratory reagent and it adjust the pt for the differing sensitivities of reagents (18).

When thrombin is added to plasma, the time required for clot formation is a measure of the rate at which fibrin forms. This test (thrombin time) yields abnormal results when the fibrinogen level is less than $70 \mathrm{mg} / \mathrm{dl}$, but it is unaffected by the levels of any of the other coagulation factors (14). For this reason, this chronometric test can be correlated with fibrinogen concentration.

All these tests must be interpreted and compared to normal plasma, or a pool of normal plasma clotting. In clinical practice we can be confronted to four different situations:

The first situation: the fibrinogen level is decreased below 0.7 $\mathrm{g} / \mathrm{l}$ (i.e thrombin time is prolonged), and then aPPT and PT are also prolonged. In this case there is not enough fibrinogen in the sample to be cleaved into fibrin, even if the levels of the other factors are in the normal ranges. (13) 
The second situation: fibrinogen and aPPT are in the normal ranges and the PT is the only prolonged time. In this case three diagnoses must come to mind: 1) factor VII deficiency either congenital (extremely rare) or acquired defects (mild vitamin $\mathrm{K}$ deficiency or mild liver disease). 2) Factor VII inhibitor (an autoimmune disease). 3) PT can be exceptionally prolonged in patients with modest decreases of factor $\mathrm{V}$ or X without affecting the intrinsic pathway $(13,18)$.

The third situation: fibrinogen and PT are normal and the aPPT is the only delayed time. This feature is met in case of: 1) A contact factor deficiency (hemophilia A or B, Rosenthal disease or Hageman disease), 2) Autoimmune inhibitors (anti-FVIII, anti-FIX, anti-FXI or antiphospholipid autoantibodies) 3) Heparin contamination of the sample (13, 18).

It is worth to remember, that in Hageman disease (Factor XII deficiency) patients are totally asymptomatic (no hemorrhage) and the prolonged aPPT is the only sign of disease, and the most astonishing event is that Hageman factor was first discovered in 1955 when a routine preoperative blood sample of the 37-year-old railroad brakeman John Hageman (1918) was found to have prolonged clotting time in test tubes, even though he had no hemorrhagic symptoms. Hageman was then examined by hematologist Oscar Ratnoff, who found that Hageman lacked a previously unidentified clotting factor (19).

The forth situation: both tests (PT and aPPT) are prolonged with normal fibrinogen concentration. In this case four diagnoses must be evocated: 1) Factor V; X or II deficiency or inhibitor, 2) Improper anticoagulant ratio (hematocrit below $15 \%$ or above $60 \%$ ), 3) High doses of Heparin (elevation of aPPT greater relatively to PT), 4) Large vitamin K antagonist effect (elevation of PT greater relatively to aPPT). $(13,18)$

\section{CONCLUSION ET PERSPECTIVES}

CBC and coagulation screening assays are one of the most prescribed laboratory tests, and their disturbance can lead to more investigations and specific testing. As it has been demonstrated here above these parameters can be disturbed in every clinical situation and not only in hematologic disorders, that is why physicians must be well trained with these later in order to well deal with these laboratory modality in their everyday practice.

Conflicts of Interest: Authors have no conflicts of interest to declare.

\section{RÉFÉRENCES}

1. Schiller GJ. Chronic leukemias and lymphomas (Biology, pathophysiology, and clinical management). Totowa, New Jersey : Humana Press, 2003.

2. Hoffbrand av, catovsky d, tuddenham edward gd. Postgraduate haematology. 5th ed. Oxford, England: Blackwell Publishing, 2005.

3. Bain bj. Blood cells (a practical guide). 4th ed. London, England: Blackwell Publishing, 2006.

4. Bain BJ, Lewis SM, Bates I. Basic haematological techniques. In: Lewis SM, Bain BJ, Bates I, editors. Dacie and Lewis: Practical Haematology. 10th ed. Philadelphia: Churchill Livingstone, 2006: 26-54.

5. Lentowski L, Ciesla B. Basic procedures in a hematology laboratory. In: Ciesla B, editor. Hematology in practice. Philadelphia: F.A. Davis Company; 2007. p. 297-330.

6. Tkachuk DC, Hirschmann JV. Wintrobe's Atlas of Clinical Hematology, 1st Ed. Lippincott Williams \& Wilkins 2007.

7. Provan D, Singer CRJ, Baglin T, Lilleyman J. Oxford Handbook of Clinical Haematology. 2nd Ed. New York, USA: Oxford University Press 2004.

8. Brahimi $\mathrm{M}$ et al. How we assess adequacy of fine-needle aspiration materials intended for flow cytometric analysis. Hematol Oncol Stem Cel Ther 2011; 4(1): $37-40$.

9. International Council for Standardization in Haematology: Expert Panel on Cytometry Recommendation of the International Council for Standardization in Haematology on reporting differential leucocyte counts. Clin Lab Haematol 1995; 17: 113.

10. Charie LA, Harrison P, Smith CU, Cobb JR, Briggs C, Machin S. Accuracy in the low platelet count range: a comparison of automated platelet counts on Beckman Coulter high-volume hematology analyzers with the ISLH/ICSH platelet reference method. Lab Hematol 2001;7:236-44.

11. Rowan RM. Platelet counting and the assessment of platelet function. In: Koepke JA, editor. Practical Laboratory Hematology. New York, NY: Churchill Livingston, 1991: 157-70.

12. Brahimi M, Osmani S, Arabi A, Enta-Soltan B, Taghezout Z, Smain Elkahili B, et al. The estimation of platelet count from a blood smear on the basis of the red cell platelet ratio. Turk J Hematol 2009;26:21-4.

13. Arabi A, Brahimi $M$, Benzineb B, Bekadja MA. L'hémostase!!! C'est facile. Oran, Algeria: Edition Dar El Gharb, 2009.

14. Greer JP, Foerster J, Rodgers GM, Paraskevas F, Glader B, Arber DA, Means RT. Wintrobe's Clinical Hematology. 12th ed. Philadelphia, PA, USA, Lippincott Williams \& Wilkins, 2009.

15. Provan D. ABC of Clinical haematology. 2nd ed. London, UK. BMJ Books, 2003.

16. Belhani M, Hariti G, Cherif N, Brahimi M. Guide pour le diagnostic clinique et biologique de l'hémophilie et des autres désordres hémorragiques héréditaires. Novonordisk edition, 2014.

17. Bezeaud A., Guillin MC.Physiologie de la coagulation EMC Hématologie 2001, 13-019-A-20.

18. DeLoughery TG. Vademecum: Hemostasis and Thrombosis. 2nd ed. Georgetown, Texas, USA. Landes Bioscience 2004

19. Ratnoff OD, Margolius A. "Hageman trait: an asymptomatic disorder of blood coagulation". Transactions of the Association of American Physicians 1955; 68: 149-54.

Cet article a été publié dans le « Batna Journal of Medical Sciences » BJMS, I'organe officiel de "I'association de la Recherche Pharmaceutique - Batna »

Le contenu de la Revue est ouvert "Open Access » et permet au lecteur de télécharger, d'utiliser le contenu dans un but personnel ou d'enseignement, sans demander l'autorisation de l'éditeur/auteur.

Avantages à publier dans BJMS :

- Open access : une fois publié, votre article est disponible gratuitement au téléchargement

- Soumission gratuite : pas de frais de soumission, contrairement à la plupart des revues « Open

Access »

- Possibilité de publier dans 3 langues : français, anglais, arabe

- Qualité de la relecture : des relecteurs/reviewers indépendants géographiquement, respectant

l'anonymat, pour garantir la neutralité et la qualité des manuscrits.

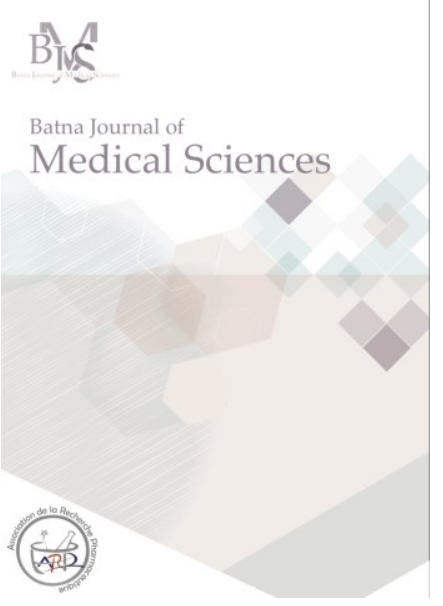

